\title{
DISCUSSION
}

\section{SUSTAINABLE EDUCATION FOR FUTURE MANAGERS AND ENTREPRENEURS}

Corporations paying attention only to short-term profits risk losing their stakeholders' trust. The current global economic crisis challenges especially universities and business schools to minimize this risk. The education of future managers and entrepreneurs should respond not only to economic requests but also to the demands of the social and ecological environments. It should sensitize them to the long-term impacts of their activities on all involved stakeholders, whose reactions to negative externalities can harm companies' success considerably. For instance, customers all over the world have lost trust in banks due to bad investment-counseling, serving themselves rather than their clients' interests. Consequently, customers withdrew their assets and invested them in more "trustworthy" institutions.

Besides emphasizing cost-efficiency and profitability management, education should consider its effectiveness for future generations. Thus, "sustainable education" has become a top issue for discussion.

The reasons to integrate "Sustainable Corporate Responsibility" into the daily work of future managers and entre- preneurs are the increasing global transparency disclosing corporate misbehavior, stronger demands of stakeholders as well as the decreasing resources from which everyone lives.

In order to survive in the long run, companies have to get along well with all of their stakeholders and to act meaningfully. They have to take on "Sustainable Corporate Responsibility" (SCR), a holistic concept which is explained in a separate paper of this issue.

By all means, future managers and entrepreneurs should be sustainably educated in order to learn how to take on Triple Corporate Responsibility: besides the economic responsibility, they should equivalently also take on social and ecological responsibility, all preferably long-lasting.

\section{Author}

Prof. Dr. phil. Mathias Schüz Deputy Head of Center for International Business School of Management and Law at Zurich University for Applied Sciences Stadthausstrasse 14, CH-8401 Winterthur mathias.schuez@zhaw.ch 